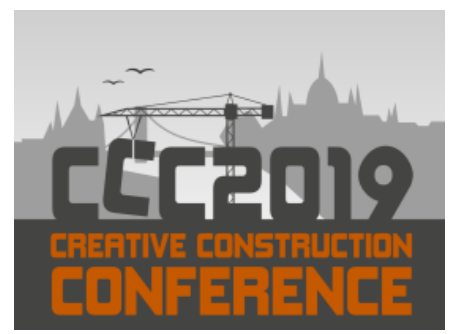

Available online at 2019.creative-construction-conference.com/proceedings/

CCC 2019

Proceedings of the Creative Construction Conference (2019) 018

Edited by: Miroslaw J. Skibniewski \& Miklos Hajdu

https://doi.org/10.3311/CCC2019-018

Creative Construction Conference 2019, CCC 2019, 29 June - 2 July 2019, Budapest, Hungary

\title{
Innovative Stay-in-Place Formwork Method for Reinforced Concrete Columns
}

\author{
Kim, Wontae ${ }^{\mathrm{a} *}$, Kim, Sungjig ${ }^{\mathrm{b}}$, Kim, Siyun ${ }^{\mathrm{b}}$ \\ ${ }^{a}$ Yonsei University, 50 Yonsei-ro Seodaemun-gu, Seoul, 03722, Republic of Korea \\ ${ }^{b}$ Keimyung University, 1095 Dalgubeol-daero, Dalseo-gu, Daegu 42601, Republic of Korea
}

\begin{abstract}
Recent earthquakes at Pohang in Korea have caused significant damages to existing reinforced concrete (RC) structures. Particularly, piloti columns of RC structures suffered considerable damages. The objective of this research is to review the feasibility of an innovative stay-in-place formwork method using the Textile Reinforced Concrete (TRC) for RC columns in order to improve seismic performance and reliability. The scope of the study includes 1) a development of a concept for TRC stay-in-place form for $\mathrm{RC}$ columns, and 2) designing and manufacturing of TRC form modules. It is expected that structural damage of the property, human injuries or loss of life caused by future earthquakes can be reduced by improving the seismic performance using TRC sitein-place participating form, which can also save the social cost for the recovery from the disaster.
\end{abstract}

(C) 2019 The Authors. Published by Budapest University of Technology and Economics \& Diamond Congress Ltd. Peer-review under responsibility of the scientific committee of the Creative Construction Conference 2019.

Keywords:Textile Reinforced Concret ; Stay-in-place Form; Seismic Performance; Reinforced Concrete Column; Earthquake; Piloti Structure

\section{Introduction}

\subsection{Background}

On November 15, 2017, a total of 31,000 structures, including houses, shops, and factories, were damaged by a 5.4magnitude earthquake in Pohang, South Korea. Among the facility damages, the column failures of the reinforced concrete piloti structures of low-rise houses were severe. The causes of the damages of the piloti structures were shown to be associated with the insufficient facility design and construction procedure, such as the eccentricity of the core wall, the shortage of the shear reinforcement of the column, the non-compliance of the detailed construction standard, etc. [1]. Seismic design standards have not been properly applied to the piloti structures, and construction quality control has not been properly performed to ensure seismic performance of such structures. Fig. 1 shows several example cases of column failures of piloti structures in Pohang. In the columns of the piloti structures, the designed cross section was not properly secured due to an excessive concrete cover of $100 \mathrm{~mm}$ thickness and an inclusion of drainage pipes in the column member. The spacing of the shear reinforcement far exceeded the design standard of 152 $\mathrm{mm}$ to $260 \mathrm{~mm}$. The poor anchorage of tie, which did not to comply with hook detail standards were also observed.

*Corresponding author: Kim, Wontae email: wontkim@hotmail.com 
Kim, Wontae, et al. / Proceedings of the Creative Construction Conference (2019) 018

https://doi.org/10.3311/CCC2019-018

The first floor piloti columns of RC structure are the core members to support the entire structure. In the event of an earthquake, the vulnerability of the piloti column can be directly linked to the risk of property damage and loss of life because it could be extended by the collapse of the entire structure. In other words, securing the structural performance of the piloti columns is a prerequisite for ensuring the stability of the entire structure. However, in the case of domestic small piloti buildings, seismic performance of structures has not been fully guaranteed as confirmed in the earthquake damages in Pohang. The root cause of this problem can be pointed out to the poor working environments in which small low-rise piloti structures are constructed. Most of these facilities are constructed by small-to-medium sized construction companies with insufficient construction management capacity or employing low-skilled workers. It may often be observed that the details of design documents are insufficient, the workers' understanding of the seismic details is unsatisfactory, or construction criteria are not completely met. Consequently, it is assumed that the variation of the seismic performance of the piloti columns is considerably large at the small low-rise piloti structures in Korea.

\subsection{Objective and Scope}

An alternative technology to improve the seismic performance of domestic RC piloti structure, which is currently exposed to the risk of earthquake, is urgently needed. The purpose of this study is to investigate the technical validity of the method to secure the seismic performance by using the permanent stay-in-place formwork using the textile reinforced concrete (TRC) for the columns of RC structures. The scope of the study includes 1) a development of a concept for TRC stay-in-place form for RC columns, and 2) designing and manufacturing of TRC form modules.
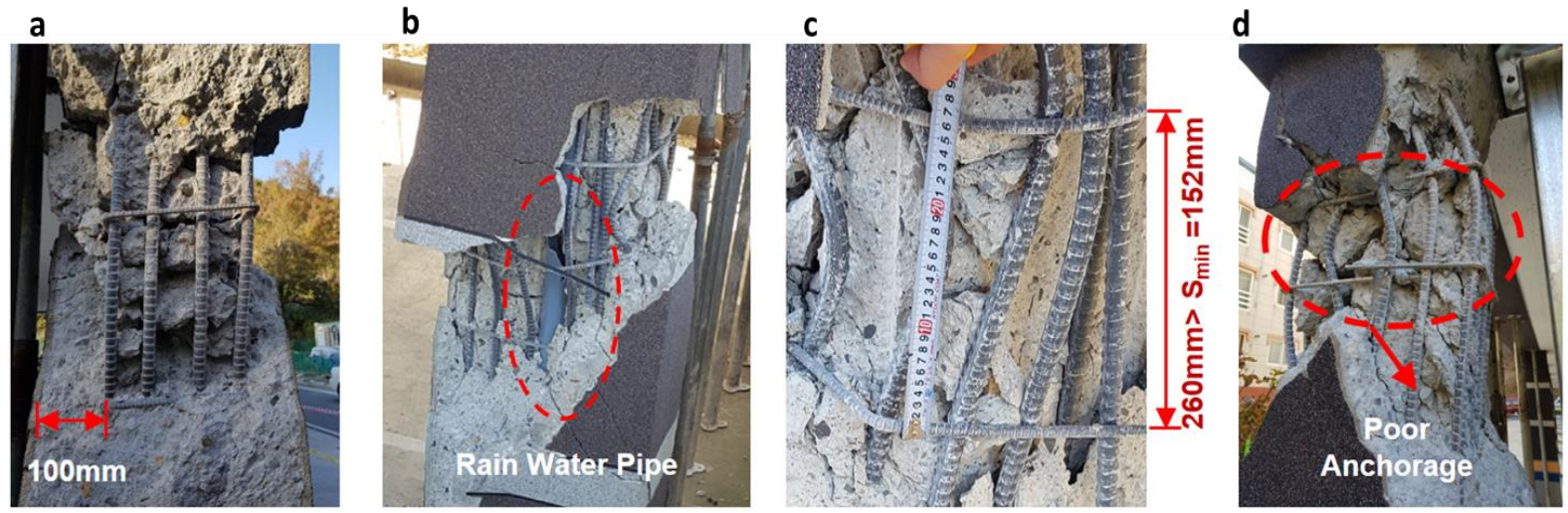

Fig. 1. Examples of Column Failures of Piloti Structure in Pohang, Korea: (a) excessive concrete cover; (b) inclusion of rain water pipe; (c) inappropriate spacing of ties; (d) poor anchorage of ties (non-appliance of hook detail standards)

\section{Concept of Stay-in-Place Formwork and Textile Reinforced Concrete}

Conventional temporary formwork methods of RC structure have long been a target area of innovation in construction sites. There are two underlying reasons. First, there is a certain limitation to shorten the construction duration since the $\mathrm{RC}$ work is sequentially conducted such as in the order of temporary formwork installation, reinforced bar assembly, concrete pouring and curing, formwork removal, and finishing work. Second, there is a difficulty in managing the quality of work depending on various working conditions due to the characteristics of outdoor environment as the most of related work are performed on-site, leading to a large amount of deviation in work quality. Moreover, the outstanding issues of the shortage of skilled workers and the aging of workers also exacerbates the problem of construction cost increase in Korea. Thus, many attempts have been constantly made to develop a more innovative stay-in-place formwork system method, which can be carried out in parallel with precise factory pre-fabrication and site installation of the RC member required in the structure while shortening the construction duration by skipping the formwork removal process. Early attempts were to develop a permanent formwork system using general single materials such as 
Kim, Wontae, et al. / Proceedings of the Creative Construction Conference (2019) 018

https://doi.org/10.3311/CCC2019-018

wood, steel, etc. However, practical use of such system was constrained to a limited extent due to the diverse problems such as formability, durability, and economical feasibility.

Development of stay-in-place formwork systems with new composite materials were attempted. Studies on the development of permanently fixed formwork using fiber-reinforced-polymer based concrete have been performed [2, 3]. However, they have not yet been put to practical use due to the drawbacks of low resistance to fire despite their excellent structural performance. Another attempt to develop a stay-in-place form was to utilize Textile Reinforce Concrete (TRC). The concept and advantages of TRC can be summarized as shown in Fig. 2. TRC can be defined as a composite material in which continuous textile fabric are integrated with portland cement and a cement matrix composed of fine aggregates. The TRC possesses high tensile strength due to the characteristics of textile fibers, and also has excellent advantages with respect to high durability, corrosion free, formability, and light weight.

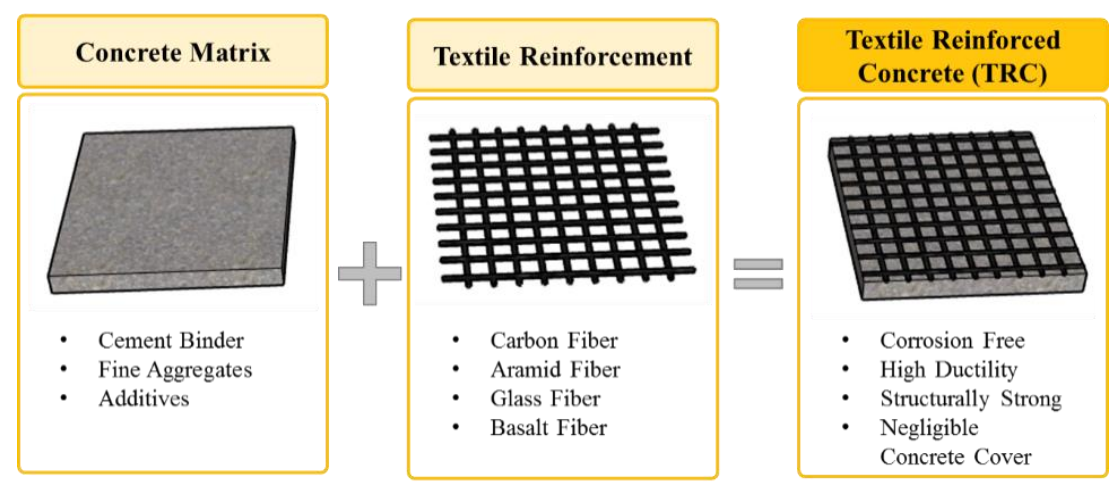

Fig. 2. Concept and advantages of Textile Reinforced Concrete

As shown from a result of flexural and tensile tests at the material level in Fig. 3, a brittle failure was observed for control experimental specimen without textile fabric, but a progressive failure was observed for the TRC panel, which showed high flexural strength and toughness. By utilizing these advantages of the TRC panel, it is possible to provide the formwork function for construction of reinforced concrete structure and also to improve the seismic performance of the structural member.

a

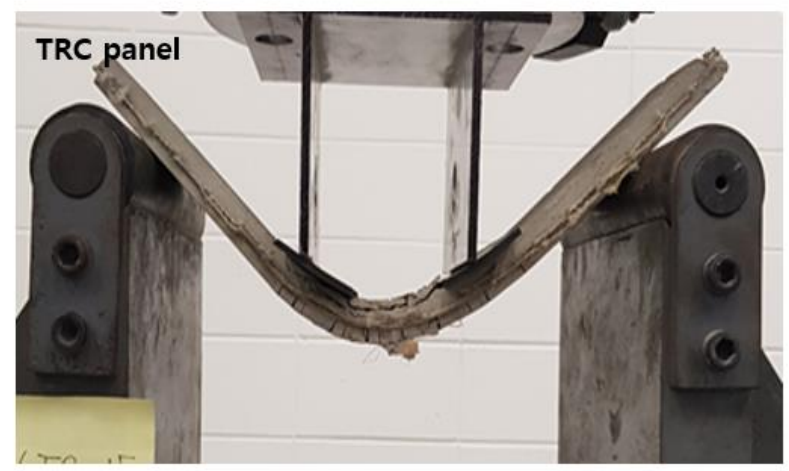

b

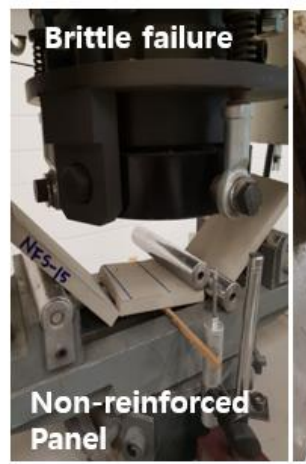

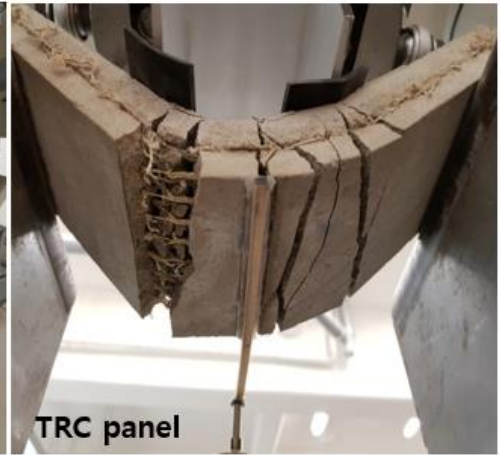

Fig. 3. Tests of TRC panel: (a) flexural test; (b) comparison of failure modes between non-reinforced panel and TRC panel

In the past studies, the development of stay-in-place formwork using TRC has been conducted around horizontal members such as slabs and beams [4, 5, 6, 7]. Recently, experimental works on the performance of TRC stay-in-place formwork applied for a vertical member such as columns $[8,9]$ and an asymmetric shell structure [10] have also been performed. Existing studies have demonstrated that the structural performance of a column using TRC is superior to 
Kim, Wontae, et al. / Proceedings of the Creative Construction Conference (2019) 018

https://doi.org/10.3311/CCC2019-018

that of a conventional RC column through the experimental test of specimens. On the other hand, there has been no study on the design and construction methodology of the stay-in-place form module targeting for the commercialization of such technology by considering constructability and economical feasibility. In particular, there have been no studies on the stay-in-place TRC formwork method to improve the seismic performance of piloti columns that are vulnerable to earthquakes. In this study, the prototype of the TRC stay-in-place modular member was designed and fabricated based on the results of reviewing the validity and applicability to the piloti columns.

\section{Design and Manufacture of TRC Stay-in-Place Formwork Modules for Concrete Columns}

\subsection{Modulization of TRC Form}

The division of the panel module was considered for 1) the convenience of transportation and operation, 2) the efficiency of production and installation, and 3) the time and cost. This study focuses on the development of stay-inplace formwork for rectangular columns which is most frequently used in small residential facilities. For casting and curing of concrete, the TRC permanent forms should be located at four sides of columns and assembled. The weight of TRC form was estimated to be approximately $53 \mathrm{~kg}$ when the TRC permanent form with thickness of $40 \mathrm{~mm}$, height of $1,000 \mathrm{~mm}$, and the cross sectional area of $400 \mathrm{~mm}$ x $400 \mathrm{~mm}$ was placed without any division. Considering the weight of the member and the convenience of transportation, it is advantageous as the division of the panel section increases. For example, as shown in Fig. 4, when dividing into two sections, the weight of the unit member becomes $27 \mathrm{~kg}$, and when divided into four equal sections, it can be reduced to $13 \mathrm{~kg}$. However, if the section division of panel modules results in the increase factory manufacturing time and site installation (due to the increased time for assembly of each forms), the efficiency of the work is reduced and the costs of production and installation of TRC formwork members are increased. In addition, there is a disadvantage in that the stability of structural elements may be decreased due to an increase in the number of joint elements of the TRC modules by the sectional subdivision. Therefore, no sectional division in the shape type module was considered in this work for the development of TRC stay-in-place formwork for RC columns.

a

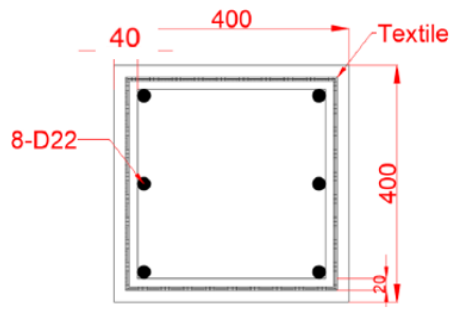

b

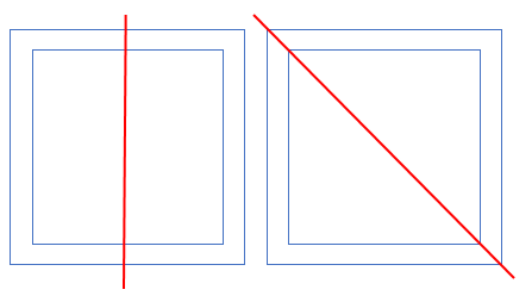

C

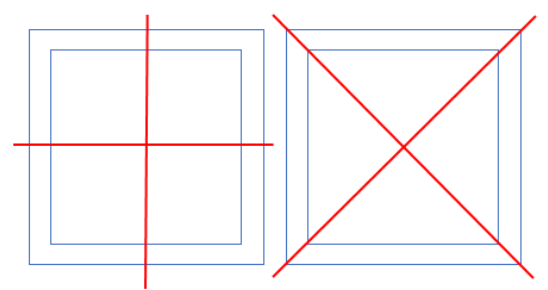

Fig. 4. Review of Module Division Alternatives of Textile Reinforced Concrete: (a) no division (53kg); (b) 2 sections (27kg); (c) 4 sections $(13 \mathrm{~kg})$

Since the design of the building (especially for the height of floor) is different from each other, there is a problem with difficulty in standardization for the production of the members in advance. If the TRC stay-in-place form elements can be mass-produced by modularization, the time and expense for manufacture and installation can be saved significantly. In order to realize these benefits, this study suggests a vertical modularization scheme which allows a standard prefabrication of bottom module regardless of the floor height, as shown in Fig. 5. The TRC form module applied on top of the RC columns is prefabricated in a custom-made modular method according to the planned floor height. Concave and convex grooves at both ends of the modules are designed for the easy connection of the upper and bottom TRC modules on site. In addition, the pre-processed holes for the insert of shear key to fasten the upper and bottom modules are suggested. 
Kim, Wontae, et al. / Proceedings of the Creative Construction Conference (2019) 018

https://doi.org/10.3311/CCC2019-018
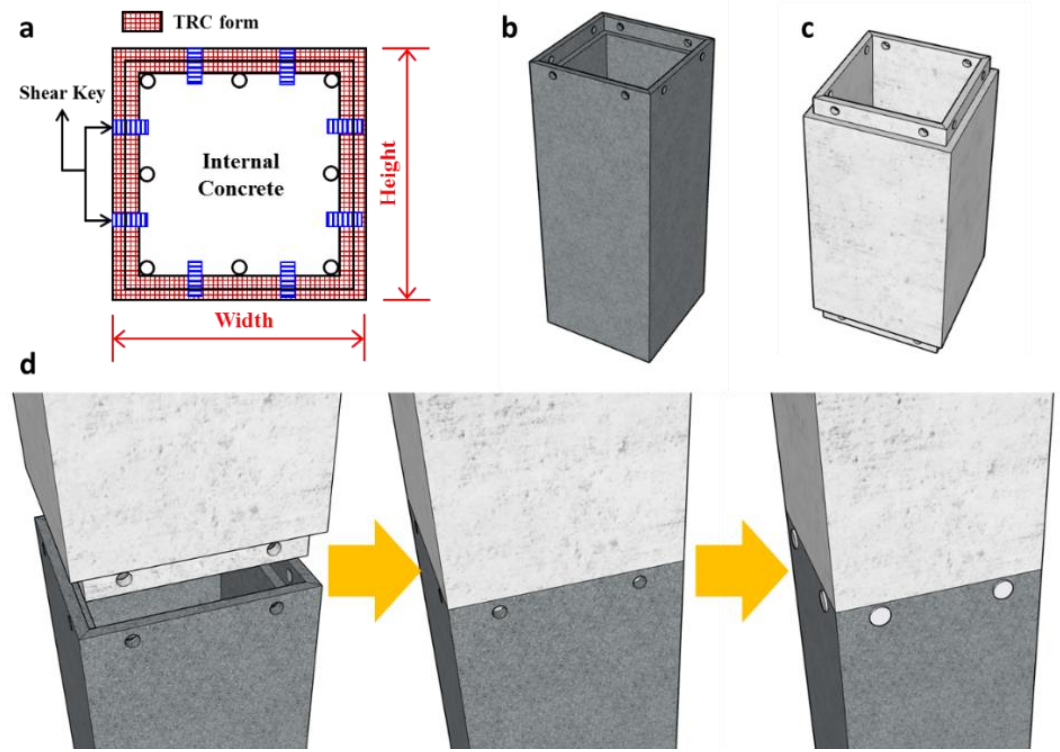

Fig. 5. Development of TRC Form Module: (a) section of TRC form module; (b) bottom module; (c) upper module; (d) connection between upper and bottom modules

\subsection{Manufacture of TRC Form Module}

A mold for the production of TRC stay-in-place form module was designed and manufactured as shown in Fig. 6. The mold of TRC shaft form module was made of steel for durability and repeated use. Outer panel of the mold can be folded out to facilitate easy removal of the form after textile fabric installation, casting and curing of concrete. The inner panels of the mould is able to be folded inward when the bolts are unscrewed to minimize damage during removal work of the TRC shaft module.

\section{a}

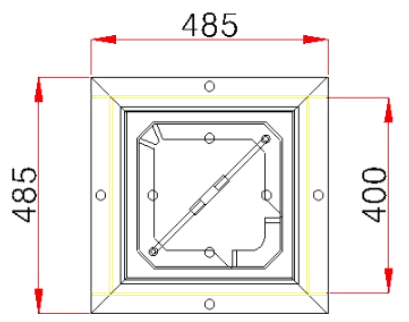

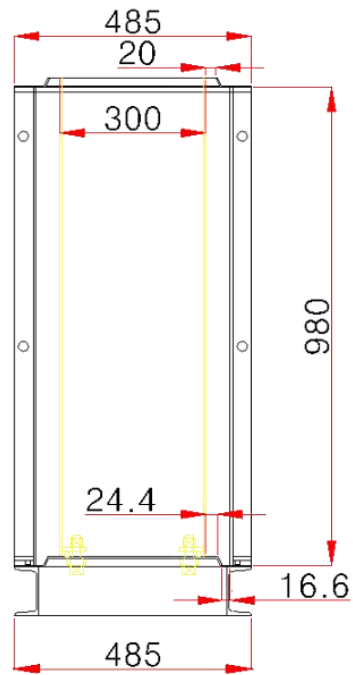

b

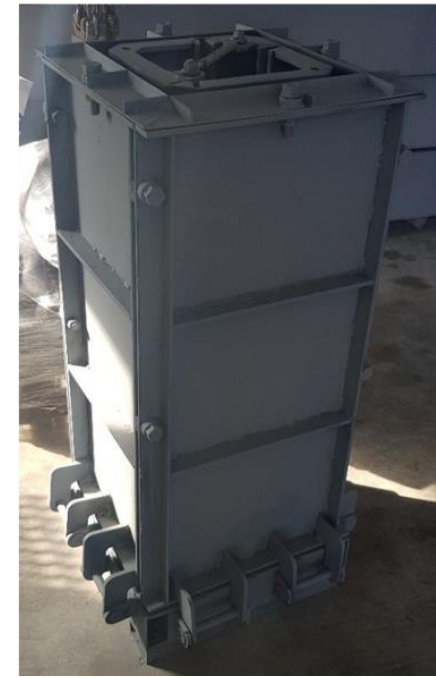

Fig. 6. (a) Mold design for TRC site-in-place form; (b) Mold production for TRC stay-in-place form

A prototype TRC stay-in-place was produced as shown in Fig. 7. After opening the outer panel of mold, textile fabric was installed at the planned position by using inner spacer at the mold. The outer panel of the TRC mold was sealed 
Kim, Wontae, et al. / Proceedings of the Creative Construction Conference (2019) 018

https://doi.org/10.3311/CCC2019-018

in order to place fresh concrete. When the outer and inner panels were removed after curing for a sufficient period of time, the TRC stay-in-place form module was finally produced.

a

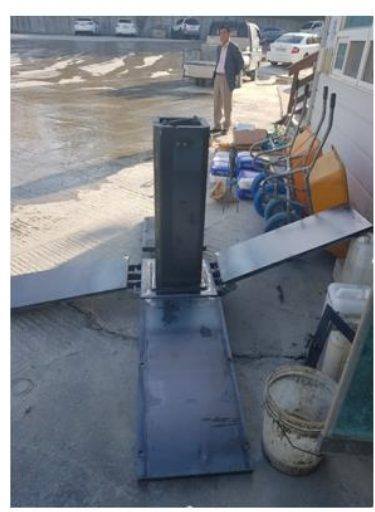

b

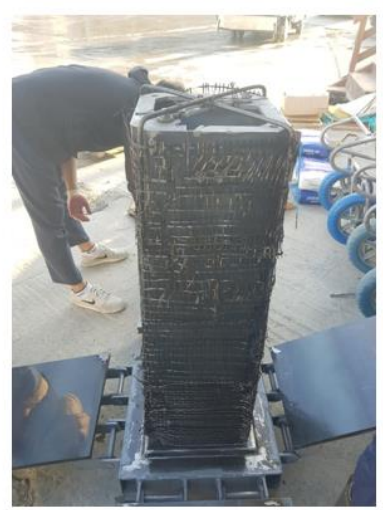

C

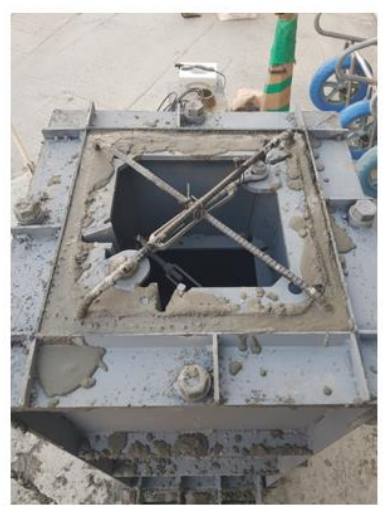

d

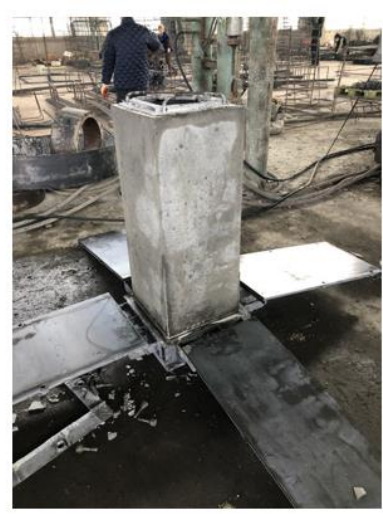

Fig. 7. (a) Opening of TRC form mold; (b) installation of textile; (c) placing of concrete and curing; (d) completed TRC module shaft

\section{Conclusion}

In this study, the design and construction method of the innovative stay-in-place formwork to secure the seismic performance of the column of the RC structure was proposed by utilizing a new composite material of TRC. The rectangular cross section of the TRC stay-in-place form module was proposed. The division of the TRC stay-in-place module was not considered due to the constructability and the stability of structural elements after the connection of form elements. In addition, in order to adapt for the changes in the height of RC columns, modularization method of TRC form divided into upper and lower part was proposed. In the following study, evaluation of seismic performance of RC columns using TRC stay-in-place formwork, evaluation of field applicability for practical use, and comparative productivity and economic evaluation work compared with the conventional methods are planned to be carried out. It is expected that it will reduce the damage of structures due to natural disasters such as earthquakes through securing the seismic performance through the TRC stay-in-place form, and also reduce the social cost for recovery after the disaster.

\section{Acknowledgements}

This work was supported by a grant (19RDRP-B076268-06) from Land Transport Technology Area Specialization Program funded by Ministry of Land, Infrastructure, and Transport of Korean Government.

\section{References}

[1] Oh, S.H. (2017). Report of Pohang Earthquake Damage and Policy Proposal, Korea-Japan Building Earthquake Damage Academic Seminar.

[2] Deskovic, N., Meier, U., \& Triantafillou, T. C. (1995). Innovative design of FRP combined with concrete: long-term behavior. Journal of Structural Engineering, 121(7), 1079-1089. https://doi.org/10.1061/(ASCE)0733-9445(1995)121:7(1079)

[3] Hall, J. E., \& Mottram, J. T. (1998). Combined FRP reinforcement and permanent formwork for concrete members. Journal of Composites for Construction, 2(2), 78-86. https://doi.org/10.1061/(ASCE)1090-0268(1998)2:2(78)

[4] Curbach, M., \& Jesse, F. (1999). High-performance textile-reinforced concrete. Structural engineering international, 9(4), $289-291$. https://doi.org/10.2749/101686699780481745

[5] Brameshuber, W., Koster, M., Hegger, J., Voss, S., Gries, T., Barle, M., ... \& Kruger, M. (2004). Textile reinforced concrete (TRC) for integrated formworks. Special Publication, 224, 45-54.

[6] Verbruggen, S., Remy, O., Wastiels, J., \& Tysmans, T. (2013). Stay-in-place formwork of TRC designed as shear reinforcement for concrete beams. Advances in Materials Science and Engineering, 2013. http://dx.doi.org/10.1155/2013/648943

[7] Huang, B. T., Li, Q. H., Xu, S. L., \& Li, C. F. (2017). Development of reinforced ultra-high toughness cementitious composite permanent formwork: Experimental study and digital image correlation analysis. Composite Structures, 180, 892-903. https://doi.org/10.1016/j.compstruct.2017.08.016 
Kim, Wontae, et al. / Proceedings of the Creative Construction Conference (2019) 018

https://doi.org/10.3311/CCC2019-018

[8] Papantoniou, I. C., \& Papanicolaou, C. G. (2008). Textile reinforced concrete (TRC) for precast stay-in-place formwork elements. Tailor made concrete structures, $475-481$.

[9] Papanicolaou, C. G., \& Papantoniou, I. C. (2010). Mechanical behavior of textile reinforced concrete (TRC)/concrete composite elements. Journal of Advanced Concrete Technology, 8(1), 35-47. http://dx.doi.org/10.3151/jact.8.35

[10] Verwimp, E., Tysmans, T., \& Mollaert, M. (2016). Numerical evaluation of structural stay-in-place formwork in textile reinforced cement composite for concrete shells. Advances in Structural Engineering, 19(9), 1500-1513. http://dx.doi.org/10.1177/1369433216643895 